BULLETIN Bulletin hispanique

HISPANIQUE Université Michel de Montaigne Bordeaux

$115-2$ | 2013

Les traductions vieillissent-elles?

\title{
De nuevo ante el soneto de Góngora «Restituye a tu mudo horror divino»
}

el texto en su verdadero contexto

\section{Begoña López Bueno}

\section{(2) OpenEdition}

\section{Journals}

Edición electrónica

URL: http://journals.openedition.org/bulletinhispanique/2911

DOI: 10.4000/bulletinhispanique.2911

ISSN: 1775-3821

Editor

Presses universitaires de Bordeaux

Edición impresa

Fecha de publicación: 28 diciembre 2013

Paginación: 725-748

ISBN: 978-2-86781-908-7

ISSN: 0007-4640

Referencia electrónica

Begoña López Bueno, « De nuevo ante el soneto de Góngora «Restituye a tu mudo horror divino» », Bulletin hispanique [En línea], 115-2 | 2013, Publicado el 14 febrero 2017, consultado el 01 mayo 2019. URL : http://journals.openedition.org/bulletinhispanique/2911; DOI : 10.4000/bulletinhispanique.2911 


\title{
VARIA
}

\section{De nuevo ante el soneto de Góngora «Restituye a tu mudo horror divino»: el texto en su verdadero contexto}

\author{
Begoña López Bueno \\ Universidad de Sevilla
}

Le sonnet de Gongora "Restituye a tu mudo horror divino " passe pour être l'un des plus énigmatiques de son auteur. Ce travail en propose des lectures interprétatives novatrices et le replace dans le contexte conflictuel qu'a représenté pour Gongora l'année 1615.

Mots clés: Gongora, sonnet "Restituye a tu mudo horror divino ", polémique gongorine.

El soneto de Góngora "Restituye a tu mudo horror divino" pasa por ser una de las composiciones más enigmáticas de su autor. En este trabajo se proponen novedosas lecturas interpretativas del mismo y se le sitúa en el conflictivo contexto que el año de 1615 supuso para Góngora.

Palabras claves: Góngora, soneto "Restituye a tu mudo horror divino», polémica gongorina.

Gongora's sonnet, "Restituye a tu mudo horror divino" is one of the most enigmatical poems written by the author. The present article proposes original interpretations of the sonnet attending to the controversial context of 1615, which was a situation of special conflict for Gongora.

Keywords: Góngora, sonnet "Restituye a tu mudo horror divino», controversy of Góngora. 


\section{En homenaje a Antonio Carreira, por su extraordinaria aportación al gongorismo}

$\mathrm{E}$ 1 año de 1615 fue de especial dificultad para Góngora por el carácter y la entidad que tomaron las censuras contra sus poemas mayores, en especial el tan polémico Antídoto contra la pestilente poesía de las Soledades de Juan de Jáuregui. Junto a reacciones satíricas, el soneto "Restituye a tu mudo horror divino» representa la respuesta dolorida y defensiva de quien vio seriamente vilipendiada su manera de hacer y entender poesía. Por eso, y para su cabal comprensión, resulta imprescindible recrear el contexto con el que el soneto dialoga de manera tácita, aspecto al que se dedica la segunda parte de este trabajo, una vez analizada la literalidad del texto con propuestas de lecturas que modifican algunas interpretaciones tradicionales del soneto, en particular las referidas al destinatario del segundo cuarteto y a la identificación de la doliente tórtola de los tercetos ${ }^{1}$.

Con toda probabilidad el soneto objeto de este análisis estaba entre las composiciones para las que don Antonio Chacón, mientras preparaba el ejemplar manuscrito de las Obras de D. Luis de Góngora², solicitó información precisa del autor: «... le pedí me informasse de los casos particulares de algunas cuia inteligencia depende de su noticia $»^{3}$. Sin duda bastantes o muchas de estas obras que requerían noticia del propio autor, y desde luego el soneto en cuestión, coincidirían con las que necesitaban asimismo de un título para su cabal comprensión, tal como declara el mismo Chacón en la primera de

1. Tras haber publicado una primera versión de este trabajo (López Bueno, 2009), las profundas revisiones a que lo he sometido en su segunda parte, que pasa a ser completamente distinta, aconsejan esta nueva publicación. Dichas revisiones proceden de parte de las conclusiones a las que he llegado en cuatro trabajos recientes (López Bueno, 2011, 2012a, 2012b y 2013).

2. Obras de D. Luis de Góngora, reconocidas y comunicadas con él, por D. Antonio Chacón Ponce de León, Señor de Polvoranca... Divididas en tres tomos. Se trata de un manuscrito de preciosa caligrafía y copiado en fina vitela, que su recopilador dedicó al Conde-Duque en diciembre de 1628. Según allí se afirma, la colección se preparó bajo la vigilancia del propio Góngora, lo que la convierte en la mejor de las antiguas, en el codex optimus entre los abundantes manuscritos integri que circularon de la obra del poeta cordobés. Para conocer el alcance e importancia de esta colección son imprescindibles, entre otros, los trabajos que figuran al frente de los tomos II y III de la edición facsímil (1991) debidos respectivamente a M. Sánchez Mariana (1991) y a A. Carreira (1991), así como el de J. M. Micó (2007).

3. La frase en cuestión adquiere su pleno sentido en la relación del conjunto de tareas que Chacón, en la dedicatoria al Conde-Duque, dice haber asumido al recopilar las poesías de Góngora: "Quando junté todas [las obras] que la diligencia de D. Luis i la mía pudo adquirir en ocho ańos, quando trabajé con él las emendasse en mi presencia con diferente atención que solía otras vezes, i quando le pedí me informasse de los casos particulares de algunas cuia inteligencia depende de su noticia, me dixesse los sujetos de todas, i los años en que hizo cada vna, sólo tuue por fin el interés que mi affición a estas obras lograua». 
las advertencias que pone al frente de su recopilación: «Títulos. Que en solas las obras heroicas i grandes (por sí o por sus sujetos) se han puesto títulos; o en aquellas que lo han menester para inteligencia de sus materias». Cierto, porque, de haber carecido de título (y de un título tan indicativo, además), la intelección del soneto que nos ocupa hubiera sido mucho más enigmática de lo que ya es de por sí. Veámoslo tal como lo recogió Chacón ${ }^{4}$ :

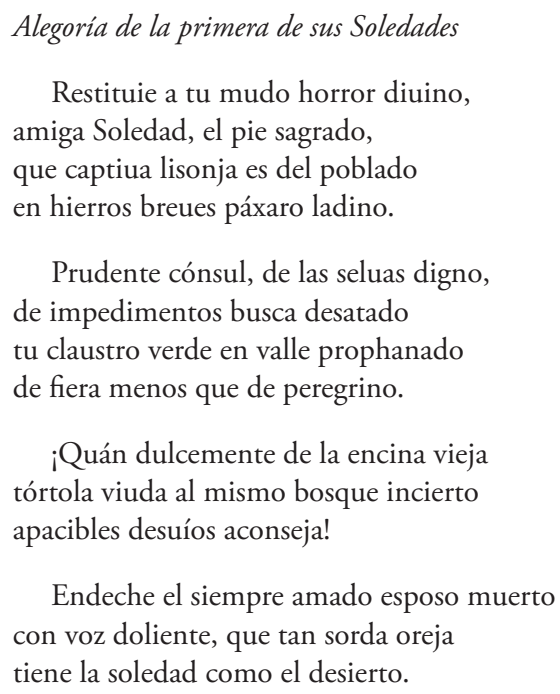

¡Quán dulcemente de la encina vieja tórtola viuda al mismo bosque incierto apacibles desuíos aconseja!

Endeche el siempre amado esposo muerto con voz doliente, que tan sorda oreja tiene la soledad como el desierto.

En orden a la interpretación que quiero defender, adelanto ya una paráfrasis explicativa como guía del análisis posterior: el poeta se dirige en los cuartetos a su propia obra, la Soledad, exhortándola, en el primero de ellos, a que vuelva a su origen, esto es, al silencio previo a la creación del poema mismo (aunque también -a tenor de lo que se dice en el segundo cuarteto- al silencio de la selva, en el sentido de 'bosque', con el que se identifica la propia Soledad). De ese silencio nunca debió salir, porque ahora, en el poblado, entre gentes que no la comprenden, es como pájaro enjaulado que inútilmente pretende, por lo cultivado y locuaz de su canto, ganarse la voluntad de aquellas gentes. Por ello la Soledad, cuyo hábitat natural son las selvas (los bosques), es como cónsul en tierra extraña: así se dirige a ella en el segundo cuarteto intentando persuadirla de que busque su propio recinto de intimidad, su claustro verde, en un lugar libre de impedimentos - no como el de ahora, se sobrentiende-, es decir, en un valle no pisado (no visitado) por nadie, salvo por peregrino (con todas las implicaciones de la palabra, desde las acepciones normales - devoto que va a visitar lugares sagrados, persona singular o extraordinaria por infrecuentehasta la referencia al protagonista del poema).

En los tercetos hay un notable cambio de rumbo y de óptica. El centro de gravedad es ahora el poeta mismo, la instancia autorial del texto. De hecho, esa instancia autorial, la voz del poeta digamos, como sujeto del enunciado había

4. Sólo modernizo acentuación, puntuación y regularización de mayúsculas/minúsculas. 
llevado la voz cantante desde el principio del soneto, exhortando a la Soledad. Pero ahora se convierte en objeto mismo de poema, en tema, podríamos decir. El poeta se repliega sobre sí mismo, reflexiona sobre lo dicho en los cuartetos y expone las consecuencias: él es como la tórtola viuda que desde su vieja encina aconseja retiros al bosque -primer terceto-; y su canto tiene la misma inutilidad que el de la tórtola -segundo terceto-, puesto que ambos se quejan en vano, ante la soledad de los bosques la tórtola y ante la Soledad-poema el poeta: ambas soledades son tan sordas como el mismo desierto.

Dos novedades aporta esta lectura del soneto. Una sobre el «prudente cónsul» del v. 5 que, contra la interpretación tradicional proveniente de Salcedo Coronel, no lo creo referido a ninguna persona, sino a la misma Soledad a la que se había dirigido el poeta en el primer cuarteto. Es verdad que semejante identificación había sido ya apuntada por M. Molho, pero en medio de una lectura un tanto simbólica, y en muchos extremos confusa, del soneto, que no ha conseguido suficiente eco crítico hasta el presente ${ }^{5}$.

La segunda novedad no tiene ningún antecedente, que yo sepa, y se sitúa en los tercetos, donde ha residido siempre la mayor dificultad interpretativa del soneto. Comúnmente se ha querido ver en ellos una identificación de la propia Soledadpoema con la tórtola. Pero semejante interpretación tiene al menos -al margen de otras más discutibles- una contraindicación seria: es la «soledad» la que está sorda ante las quejas (según se dice en vv. 13-14) y, por tanto, no puede ser ella quien a la vez emite la queja (si se identifica con la tórtola) y quien no la escucha por su «sorda oreja». Tal vez por eso la edición de Millé y Giménez acoge una variante que aparentemente podría prestar cierta lógica a la interpretación tradicional: «sorda queja» (v. 13) en lugar de «sorda oreja»". Sin embargo esa variante no está autorizada por ningún testimonio fiable, de Chacón en adelante, que ofrecen invariablemente «oreja». Por otra parte, la tórtola hace duelo por una pérdida, y aquí quien se duele, asimismo, es el poeta que 'ha perdido' a su obra y por eso la reclama. Claro que también podría entenderse que la Soledad ha perdido: ha perdido su lugar, y con él su identidad. En ese sentido confluirían la mismidad de ambos, del poeta y de su obra como proyección de sí mismo. Pero esa interpretación, que atiende a la globalidad simbólica del texto, nos llevaría casi al final del análisis y estamos en el principio.

5. M. Molho, 1960; reimpr. en 1978 (cito por esta edición). Molho en la interpretación del soneto no se refiere en ningún momento a los comentarios de Salcedo al mismo, que parece desconocer, lo que resulta chocante si tenemos en cuenta que cita con profusión en el mismo trabajo los dedicados a las Soledades por el propio Salcedo. El análisis de Molho del soneto en cuestión abunda en elucubraciones que tienden a ensombrecer la interpretación, lo que contrasta con la lectura tan sugerente y cargada de excelentes intuiciones en lo referido a la indagación del concepto de «Soledad» que hace en la primera parte de ese mismo trabajo (pp. 39-63) y sobre la que luego volveremos.

6. Los hermanos Millé dicen seguir como base textual de su edición (1951; el soneto en p. 507) a R. Foulché-Delbosc, pero en la edición de este hispanista se recoge asimismo «sorda oreja» (1921, I, pp. 225-226).

7. Véase la relación de variantes recogida en la edición de B. Ciplijauskaité, 1981 y 2007, pp. 464-466. 
Por lo demás, conviene recordar que, en la base de interpretaciones figuradas (que sin duda las hay, máxime en un texto como éste construido todo él en torno a una «alegoría», como se nos recuerda desde el título), siempre está, y de manera maravillosamente exacta en Góngora, la coherencia gramatical ${ }^{8}$. Por eso hay que hacer caso indefectiblemente a la literalidad del texto en primera instancia. Precisamente esa lectura literal es la única que propicia, a mi entender, la comprensión del texto en el sentido que he parafraseado, salvando «el salto conceptual entre cuartetos y tercetos» que Antonio Carreira, desde su interpretación de establecer la equivalencia tórtola-Soledad, denunciaba: «El soneto "Restituye a tu mudo horror divino", de 1615, es evidente que no nos entrega el eslabonamiento de sus conceptos con la lógica impecable habitual en Góngora; ello hace casi incomprensibles no los tercetos, sino su razón de ser, capa más profunda responsable de la coherencia total. Poco importa que aislados parezcan hermosos y sus versos eufónicos: la agregación de partes hermosas no hace sino resaltar el fallo orgánico del conjunto (o más bien de su percepción). También es obvio que mientras el problema no esté resuelto, huelga cualquier análisis, por sofisticado que sea, de ese soneto»⿳⺈. Ojalá que la lectura que ofrezco en estas páginas tienda a disipar dudas y a desvanecer esa sensación de «salto conceptual» incomprensible entre cuartetos y tercetos. Tan incomprensible, además, en Góngora, si se me permite el juego de palabras.

Antes de comenzar el análisis fragmento a fragmento, es preciso recordar que este soneto ha tenido su tradición exegética (no ciertamente amplia, pero tampoco inexistente, como afirmó $\mathrm{Molho}^{10}$ ), inaugurada por el amplio -y en tantos puntos esclarecedor- comentario que le dedicó Salcedo Coronel en 1644, cuya inicial declaración de conjunto sobre el soneto es muy elocuente:

Auiéndose publicado en la corte la primera Soledad de Don Luis, huuo algunos que inuidiosos o mal satisfechos de su estilo, calumniaron licenciosos lo que deuían admirar advertidos. Ofendido pues nuestro poeta escruió este soneto en que muerde con galantes alusiones la desatención de sus enemigos y persuade a su poema a que busque en sí mismo el premio que le negó la calumnia popular ${ }^{11}$.

8. «En Góngora -dice Antonio Carreira- no hay varias lecturas, como ahora se dice [...], sólo una es la buena: aquella que más se acerca a lo concebido por el poeta» (1986, p. 353). Comulgo totalmente con esta opinión, aplicable a Góngora o a cualquier otro escritor; así lo decía hace unos años: «Saludadas sean [las teorías recepcionistas del hecho literario] en lo mucho que tienen de fecundo en cuanto propugnan una experiencia lectora activa que dé respuesta al "silencio" de la obra de que hablaba Sastre. Pero siempre y cuando se reconozca ese "silencio" como un reto para el descubrimiento de la intención autorial que controla los contenidos polisémicos de un texto» (López Bueno, 1991, p. 165). Además, en el caso de Góngora el error de procedimiento ha venido a aumentarse por la consideración anacrónica de la modernidad de su obra, confundiendo una poesía barroca como la suya, obstinadamente racional y formal, con una poesía contemporánea obstinadamente irracional, o subreal, e informal.

9. 1986 , p. 355 .

10. «Es extraño que haya permanecido tanto tiempo en el olvido. La razón de este olvido no debe ser otra que la extrema y descorazonadora dificultad del texto» (1978, p. 63).

11. G. de Salcedo Coronel, 1644, p. 616. 
En el comentario de Salcedo llama la atención el detenimiento en los cuartetos (con alguna desmesura incluso, como en la explicación del término "cónsul»), en contraste con la rapidez y poca precisión con que despacha los tercetos, donde ni siquiera se para a establecer el significado de la tórtola. Desde esa lejana fecha de mediados del siglo XVII el soneto no volvió a encontrar eco crítico hasta la segunda mitad del XX. La década de los años 60, con una renovada bibliografía gongorina, conoció dos aportaciones de interés para nuestro propósito: una de M. Molho que analizó el concepto de «Soledad» en el poema mayor gongorino ${ }^{12}$ y otra de E. Orozco Díaz que indagó en la génesis del mismo y en las razones de su inacabamiento ${ }^{13}$. En ambas interpretaciones el soneto que nos ocupa resultaba medular: en la de Molho porque ayudaba a completar el diseño de un concepto que ya Góngora había perfilado en los cuatro primeros versos de la dedicatoria al duque de Béjar de la Soledad primera; en la de Orozco porque la actitud arrepentida del poeta de haber enviado el poema a la corte, que trasparentaba el soneto a las alturas de 1615, refrendaba la convicción de que Góngora había traicionado el espíritu con que las Soledades fueron concebidas y por tanto era imposible continuarlas. Por lo demás, la publicación por el mismo Orozco, también en la década de los sesenta, de varios trabajos que documentaban los pasos iniciales de la polémica, luego reunidos en el volumen En torno a las «Soledades» (1969), además de su posterior monografía Lope y Góngora frente a frente (1973), contribuyeron a que el soneto adquiriera una importante dimensión en el contexto de la polémica gongorina. Esa es precisamente la perspectiva con que lo aborda Robert Jammes ${ }^{14}$, quien, siguiendo el criterio de Salcedo Coronel de identificar el «cónsul» con un personaje histórico (Francisco de Amaya, autor del Antiantídoto ${ }^{15}$ ), hace pivotar sobre el soneto una referencia concreta de la historia de la polémica, como luego tendremos ocasión de ver.

Precisamente esa interpretación del «cónsul» del v. 5 como referida a una persona concreta y real, junto a la identificación del simbolismo de la tórtola con la Soledad-poema en los tercetos, son, a mi modo de ver, los dos extremos que han venido lastrando su exégesis, y de los que no se han librado tan atinadas anotaciones como las que le dedicaron Antonio Carreira ${ }^{16}$ o Antonio Pérez Lasheras y José María Micó ${ }^{17}$. Vayamos ya al comentario del soneto ${ }^{18}$ paso a paso.

12. $1960,1978$.

13. $1963,1969$.

14. En el utilísimo Catálogo de testimonios de la polémica que figura como Apéndice II de su edición de las Soledades, 1994 (el soneto es el número XXII del Catálogo).

15. Véase el núm. XXI del mismo Catálogo de Jammes.

16. 1986 , pp. $277-78$ y 355 ; y 2009 , pp. 524-525.

17. 1991 , p. 290.

18. A la mencionada tradición exegética del soneto gongorino hay que añadir una aportación de singular relieve de G. Poggi, 2009, cuyo conocimiento me llegó cuando ya estaban cerradas estas páginas. La doble disección a la que la mencionada investigadora somete al soneto, en un plano vertical y en un plano horizontal (centrado este en la polaridad pájaro ladino de los cuartetos y tórtola viuda de los tercetos), ofrece sutiles claves para el desciframiento de la enigmática composición. 
Restituie a tu mudo horror diuino, amiga Soledad, el pie sagrado [...]

Con el animismo habitual en la poesía de Góngora, nada extraña menos al lector que la personificación de la Soledad, máxime si, como aquí, está advertido desde el título de que se trata de una alegoría. El poeta exhorta al poema a que retroceda en su camino, a que vuelva su "pie». Doble sentido para este término en relación con el doble sentido de «Soledad», pues «pie» vale aquí también como 'pie métrico'. Es sentido figurado empleado ya anteriormente por Góngora en los versos finales de la dedicatoria al duque de Béjar de la Soledad primera ${ }^{19}$. Algunos elementos más son susceptibles de comentario en estos dos versos, comenzando por el empleo del verbo «restituir». Su sentido es aquí diáfano en su acepción culta y latinizante de 'volver a su estado anterior'. Además, la restitución lleva aparejado el valor de rectificación o enmienda (aclarado por Covarrubias: «Restituir. Vale bolver alguna cosa a su dueño o a su ser [...]. Restitución, la enmienda que se haze de lo mal llevado o en otra manera $\aleph^{20}$ ) que resulta determinante aquí: se pide a la Soledad-poema que restituya su pie al mudo horror previo, esto es, que rectifique volviendo a su estado anterior. El estado anterior es el silencio («mudo horror»), que puede entenderse asimismo en el doble plano en que se mueve todo el soneto: referido al poema, será el silencio previo a la creación; referido a la soledad, será el silencio de la selva-bosque.

Pero, ¿por qué "horror divino» y por qué «pie sagrado»? Su respuesta nos llevaría al centro de un credo estético en el que, obviamente, no podemos entrar aquí. Valga decir que es comulgante con un concepto platónico de la inspiración, según el cual la voz del poeta es algo sagrado, pues no deriva del aprendizaje del arte, sino de un don otorgado por la divinidad, equiparándose por ello a la voz del profeta ${ }^{21}$. Este concepto está en la base de las teorías sobre la vena o el furor poético, que quedaron paradigmáticamente formuladas en el diálogo IV del Cisne de Apolo (1602) del clérigo asturiano Luis Alfonso de Carvallo, donde de nuevo se vuelve a la equivalencia poeta-profeta ${ }^{22}$.

19. «Déjate un rato hallar del pie acertado / que sus errantes pasos ha votado / a la real cadena de tu escudo...», vv. 30-32 (en ésta y en sucesivas citas de las Soledades sigo la edición de Robert Jammes). Junto a "pie», es de notar asimismo el empleo del sentido figurado en "pasos», tanto en los versos que acabo de citar como en el arranque del poema: «Pasos de un peregrino son errante...», vv. 1-4. El sentido figurado de «pie» fue ya señalado por Salcedo («dixo pie sagrado por verso", 1644, p. 616).

20. 1611. Las cursivas son mías.

21. En uno de los diálogos platónicos, el Ión o sobre la Ilíada, se lee: «Porque ellos [los poetas] no hablan así a consecuencia de un arte, sino en virtud de un privilegio divino [...]. Y si la divinidad los priva de la razón, tomándolos como servidores suyos, como hace con los profetas y los adivinos inspirados, es para enseñarnos, a nosotros los oyentes, que no son ellos los que dicen cosas de tanto precio y valor -ellos no son dueños de su razón-, sino que es la misma divinidad la que habla y la que se hace oír de nosotros por intermedio de aquellos» (Platón [1993] 146-148).

22. «Y si mas quieres saber en que frisan estos dos espíritus y gracias, sábete que vn proprio premio gratificauan a Prophetas y Poetas los antiguos, que era con vna corona de laurel. Tienen 
Sorprendentemente cercanas a las afirmaciones de Carvallo resultan las escritas por Góngora en su famosa Carta en respuesta de la que le escribieron de $1615^{23}$ («Pregunto yo: ¿̨ueron útiles al mundo las poesías, y aun las profecías, que vates se llama el poeta como el profeta?»). Esa equiparación de los textos poéticos con los textos sagrados ${ }^{24}$ se inscribe en la órbita de la defensa de la oscuridad poética que resultó ser pieza dialéctica fundamental en las polémicas surgidas tras la difusión de las Soledades ${ }^{25}$, además de formar parte del importante caudal teórico sobre el ingenio y el furor ${ }^{26}$, que supuso todo un complejo acompañamiento de ataques/defensas de la obra de Góngora.

En semejante equiparación o equivalencia de lo poético con lo sacralizado y divino (argumento que se constituyó, por cierto, en imprescindible en las vindicaciones contemporáneas de la poesía ${ }^{27}$ ) se sitúa indudablemente el soneto gongorino que analizamos: a la Soledad-poema, cuyo «pie» es sagrado, se le hace petición de regreso a su «mudo horror divino». Merece ser señalado que el doble plano presente en el texto alcanza también sutilmente a «horror», pues tanto es el 'estremecimiento' previo a la creación del poema, cuanto la 'aspereza'

también común el nombre porque vates, que se dize, auimentis, igual y comúnmente significa el Propheta y al Poeta. Y los Oráculos, que eran las profecías de los gentiles, en verso dauan sus respuestas, como dize Vida en su Poética. Y en la suya Horacio, Dictae per carmina sortes. Y don Iuan Huarte dize q[ue] algunos Poetas ha avido que con el calor y furor desasido el espíritu casi del cuerpo, dizen divinidades, y lo que está por venir» (L. A. de Carvallo [1958]). Sobre la importancia de Carvallo hace ya años alertó A. Vilanova: «Es el primero de nuestros preceptistas que, no sólo se aparta de la autoridad dogmática de Aristóteles, sino que formula en su integridad una poética platónica, dando paso además a las doctrinas renovadoras de Huarte de San Juan sobre las condiciones psicológicas que ha de reunir el poeta, utilizadas ya por el Pinciano. Una curiosa mezcla de idealismo platónico y de libertad romántica que se rebela contra el dogmatismo de las reglas y de las tres unidades aristotélicas...» (1953, p. 616).

23. Sobre la asignación de la fecha de 1615 a esta carta de Góngora véanse ahora los trabajos de B. López Bueno, 2011, y J. M. Daza, 2011.

24. Que remonta a las interpretaciones alegóricas medievales, según las cuales bajo la cobertura de la letra se oculta, en los textos sagrados, un profundo simbolismo. Lo mismo-viene a decir Góngora en la citada carta- ocurre en sus Soledades, si se «tiene capacidad para quitar la corteza y descubrir lo misterioso que encubren». Todo ello fue atendido en su día por A. Vilanova, 1983. Previamente a la carta de Góngora, sobre el asunto de la poesía oscura había tratado el Abad de Rute en su Parecer sobre las Soledades, argumentando que la oscuridad de las mismas estaba injustificada porque no se aplicaba «a lo épico» ni se trataban allí «misterios de religión ni profecía». Curiosamente Góngora, conocedor sin duda del Parecer del Abad cuando escribe la carta, se vale en ella del mismo argumento (y de la misma frase bíblica: «no se han de dar las piedras preciosas a animales de cerda»), pero para aplicarlo, en sentido contrario, a su poesía (Cf. Emilio Orozco, «El Parecer del Abad de Rute sobre las Soledades [Edición y comentario de un texto inédito]», 1969a, pp. 126-127).

25. Cf. J. M. Daza, 2010.

26. En especial la Apología a favor de don Luis de Góngora de Francisco Martínez de Portichuelo, editada y estudiada por Joaquín Roses, 2007, pp. 157-243.

27. Como ha estudiado Pedro Ruiz (2010), la concepción sagrada de la palabra poéticoprofética, junto con la utilidad moral o política, la capacidad enciclopédica como compendio de saberes y el catálogo de los cultivadores ilustres, son las cuatro bazas fundamentales manejadas contemporáneamente en las vindicaciones y/o panegíricos a la poesía. 
o 'escabrosidad' del bosque solitario y sólo habitado por los dioses (con ecos virgilianos, sin $\mathrm{duda}^{28}$ : no serán los únicos en este soneto).

que captiua lisonja es del poblado

en hierros breues páxaro ladino.

La partícula «que» con valor causal introduce la justificación de la solicitud previa: la Soledad debe volver a sus orígenes solitarios porque ahora, en el poblado, es como un pájaro cautivo que emplea en vano su locuacidad. Ninguna dificultad especial presenta en su significación de conjunto esta segunda parte del cuarteto, en cuya interpretación coinciden en lo esencial todos los críticos desde Salcedo Coronel: la Soledad es ahora, en el poblado (léase en la corte; esto es, entre gentes extrañas que no la comprenden) como un pájaro enjaulado. Con todo, dos observaciones merecen ser hechas para comprender ese lenguaje en profundidad, siempre lleno de insinuaciones y significados superpuestos, de Góngora. Una sobre los «hierros breves» que aprisionan a la Soledad: lo son así como corresponden a los alambres de una jaula (plano real); pero también lo son así por las 'prisiones' métricas del poema (plano figurado); y aún más, jugando ahora con la homonimia "hierro-yerro», la alusión introduce un nuevo concepto: la Soledad está también presa por los pequeños errores (entiéndase banales, insulsos, injustificados) que han encontrado en ella los críticos del «poblado». También polisémico es el vocablo «ladino». La Soledad es un pájaro ladino, porque es locuaz y «habla -como bien parafraseó Salcedo-con elegancia y pureza nuestra lengua ${ }^{29}$. Pero, aún más, el étimo de «ladino» es «latino», con cuyo sentido está muy emparentado, como recordó Covarrubias («a los que la trabajavan [la lengua latina] y eran elegantes en ella los llamaron ladinos») ${ }^{30}$. Nuevo guiño de Góngora en alusión a su lengua, culta por excelencia en su latinización de léxico y sintaxis. Pero aún podría haber más. Covarrubias también añade que «al morisco y al estrangero que aprendió nuestra lengua, con tanto cuidado que apenas le diferenciamos de nosotros, también le llamamos ladino»: la Soledad en el poblado es un ave extraña, pero un ave extranjera que habla con propiedad y locuacidad..., un ave ladina, pues. Va a tener razón Jáuregui cuando espeta a Góngora en su Antídoto: «Casi no tiene V.m. frasis que no se pueda entender de catorce o quince maneras ${ }^{31}$; aunque, obviamente, invirtiendo la intención del polemista y por tanto valorando las polivalencias

28. Como ya anotara Carreira (2009, p. 524), el horror divino es propio de los bosques en Virgilio: Eneida I, 164-165 («tum silvis scaena coruscis / desuper horrentique atrum nemus imminet umbra»), VII, 170-172 («Tectum augustum, ingens, centum sublime columnas / urbe fuit summa, Laurentis regia Pici, / horrendum siluis et religione parentum»), VIII, 347-348 («hinc ad Tarpeiam sedem et Capitolia ducit /aurea nunc, olim siluestribus horrida dumis»).

29. 1644 , p. 617.

30. El étimo «latino» induce a pensar en la utilización de «ladino» por parte de Góngora como un cultismo semántico o de acepción. En cualquier caso, su significado no comporta aquí el habitual de 'astuto, sagaz, taimado', al menos en su deriva negativa.

31. J. M. Rico, 2002, p. 61. 
léxicas gongorinas, no como defecto por ambigüedad, sino como muestra de la riqueza extraordinaria de su lengua.

Más controvertida resulta la interpretación del segundo cuarteto, por más que mayoritariamente (o quizás por eso) se hayan seguido aquí también los puntos de vista de Salcedo Coronel.

\section{Prudente cónsul, de las seluas digno, de impedimentos busca desatado tu claustro verde en valle prophanado de fiera menos que de peregrino.}

La lógica textual (esto es, la coherencia gramatical y semántica por una parte, y por otra la coherencia poética, que tiende, por lo general, a establecer paralelos discursivos en los cuartetos) hace pensar que se continúa la exhortación comenzada en el primer cuarteto, de tal manera que "prudente cónsul» sea otra forma de dirigirse, en vocativo, a la "amiga Soledad» y «busca» sea un imperativo parejo a «restituye». Máxime si el contexto y el sentido vienen a confirmarlo, como creo. La Soledad-poema, por hallarse fuera de lugar (en el «poblado» antes dicho) es como cónsul en tierra extraña, cuando ella es digna de las «selvas». La primera evidencia que apoya la interpretación propuesta está en la asociación automática soledad-selva: nadie más digno, más merecedor, pues, de las selvas que la Soledad-poema que se identifica con ellas.

Semejante identificación, clave en el soneto, había sido ya previamente establecida en la Soledad primera. De hecho, nada menos que sobre la sinonimia soledad-selva, junto a la analogía silva-selva -según observó con agudeza M. Molho ${ }^{32}-$, se basa la compleja conceptualización de las Soledades contenida en cifra en los cuatro primeros versos de la dedicatoria al duque de Béjar:

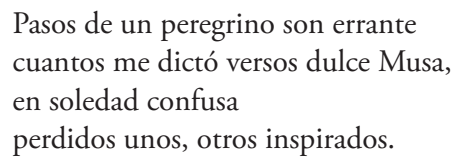

Magistral definición del poema, pues los versos dictados por la musa al poeta son [representación de] los pasos de un peregrino errante; pero mientras los unos (pasos) son perdidos, los otros (versos) son inspirados; y ambos -continúa Molho- lo son «en soledad confusa», esto es, los pasos son perdidos en una confusa selva y los versos son inspirados en una confusa silva. Si la analogía silva-selva presta a la propia estructura métrica de la silva una significación imprescindible en la vinculación entre contenido y forma ${ }^{33}$, la

32. $1960,1978$.

33. «La silva de la Soledad -dice Molho- no es solamente métrica. Informa al poema en su ordenamiento mismo, confiriéndole la característica de una soledad confusa, es decir de una silva de temas poéticos construida, según el término de Pedro Mexía, a imagen de la selva 'donde están las plantas y árboles sin orden ni regla’” (1978. p. 79). 
sinonimia soledad-selva, ya común en tiempos de Góngora ${ }^{34}$, funciona como eje sobre el que se articula todo el poema mayor gongorino. Salcedo Coronel fue extraordinariamente avispado en el reconocimiento de esta cadena asociativa selva-silva-soledad al advertir al comienzo de su comentario a las Soledades:

Este Poema que don Luis intitula Soledades (por el assunto o por el verso) es un género de composición que los Latinos llamaron Silua [...]. Presumo que don Luis quiso que esta voz Silua correspondiesse Soledad en nuestra lengua, y no impropiamente, pues si la silua significa en Castellano selua o bosque, ¿qué cosa más solitaria? Comienza pues don Luis este poema proponiendo lo que ha de cantar, y dize que el assunto de los versos que le ha dictado en la soledad su dulce Musa, es el discurso incierto de un Peregrino que en la confusión de una soledad caminó perdido ${ }^{35}$.

Esa cadena asociativa selva-silva-soledad resulta asimismo fundamental para la comprensión del soneto que comentamos, en cuya explicación continúo. La exhortación a la Soledad que se hace en el segundo cuarteto es continuidad de la hecha en el primero. Si el sitio de la Soledad está en la soledad de los bosques, debe por tanto buscar su lugar en ellos (y hacerlo con cautela; de ahí el calificativo de "prudente»), pero en el lugar más recóndito de los mismos, en la morada más protegida y secreta: el «claustro», en fin, como un lugar apartado, que es "verde», claro está, por tratarse de un lugar de la naturaleza. Ese "claustro verde» se encontrará en "valle profanado / de fiera menos que de peregrino», esto es, en un lugar, en un valle, no transitado, no pisado, no "profanado", en definitiva, por nadie antes que por "peregrino». Dos términos cargados de valores conceptuales que requieren algún detenimiento. "Peregrino» es desde luego palabra claramente polisémica aquí, pues tanto puede aludir a su significado de persona singular, extraordinaria, que guste de las Soledades acercándose a su «valle», como, en relación con el plano figurado de Soledadpoema, al protagonista del mismo; y acaso -de acuerdo con ese sentido de lectura vertical o en profundidad que Góngora reclama- la voz peregrino, como devoto que visita lugares sagrados, introduzca aquí de nuevo la connotación sacralizadora en relación con los anteriores calificativos ("horror divino», "pie sagrado») que apelaban a ese ámbito. Ello nos lleva al término "profanar».

34. Como oportunamente recuerda el mismo Molho: «Para Herrera -y para los españoles de finales del siglo XVI y del siglo XVII- una soledad es un lugar despoblado en el que la naturaleza, abandonada a sí misma, ofrece el espectáculo de una vegetación caprichosa e improductiva” (1978, pp. 49-51) Los ejemplos aducidos son elocuentes, desde Garcilaso ("Cerca del Tajo en soledad amena / de verdes sauces hay una espesura...», égl. III, vv. 57-58), pasando por Herrera (privado de su Luz, «en soledad confusa i agonía la veo oscurecida i sin aliento [...] / Cuando en l'asperidad d'el bosque espesso / m’enselvo más, la claridad s'aparta...", canción II del Libro I de Versos, vv. 21-24), hasta el mismo Cervantes en las ilusiones poético-caballerescas de don Quijote («Así como don Quijote entró por aquellas montañas [de Sierra Morena], se le alegró el corazón, pareciéndole aquellos lugares acomodados para las aventuras que buscaba. Reducíansele a la memoria los maravillosos acaecimientos que en semejantes soledades y asperezas habían sucedido a caballeros andantes» (I, XXIII).

35. G. de Salcedo Coronel, 1636, 1-1v. 
Es vocablo muy del gusto de Góngora, que emplea comúnmente con el sentido de 'entrar por primera vez en un recinto' y en contextos que poco o nada tienen que ver con la connotación negativa de hacer uso indigno de cosas respetables', y menos con el sentido más específico y asociado a lo religioso de "tratar algo sagrado sin el debido respeto' ${ }^{36}$. A no ser -como es el caso del soneto que comentamos- que lo religioso o lo divino se asocie a la consideración de un lugar natural (aquí el «claustro verde» de la selva-Soledad) cuyo 'resguardo' o 'preservación' debe mantenerse para seguir conservando su condición primigenia o prístina, y con ella su autenticidad no contaminada, no "profanada». Todo ello en línea con el ya comentado contexto de sacralización poética en que se inscribe el soneto.

Seguimos con el segundo cuarteto, en el que todavía queda un aspecto sintáctico por aclarar: «de impedimentos busca desatado / tu claustro verde». Ese estar «desatado ('libre') de impedimentos» ¿se refiere a «cónsul» o se refiere al «claustro verde»? Se viene interpretando como atribuido al primero, pero porque -desde Salcedo Coronel- se quiere ver una identificación ad hominem del supuesto cónsul. No sabría yo pronunciarme si «desatado» se refiere a la Soledad como «prudente cónsul» o a "claustro verde», aunque lo creo más bien referido a este último, sobre todo por la lógica textual que deriva del primer cuarteto: frente a la situación actual de enjaulamiento, se desea para la Soledad un lugar libre. (Aunque si lo observamos bien, es bastante insignificante que la aposición vaya referida a uno u otro término, porque resulta casi indiferente que la Soledad, ya libre de impedimentos, busque un lugar adecuado, o que el lugar que busque sea adecuado, es decir, libre de impedimentos.)

Pues bien, la interpretación tradicional de estos cuatro versos no es la que acabo de proponer. Salcedo Coronel hizo una lectura real del «prudente cónsul» en estos términos:

Alude Don Luis a la docta defensa que hizo el Doctor don Francisco de Amaya contra las objeciones que se opusieron a esta soledad, y assí dize que prudente Cónsul, digno por su ingenio de la inteligencia deste poema, buscó, librándose de los impedimentos de su profesión, su verde claustro, esto es, los estudiosos y floridos primores que contiene esta silva. Imitó Don Luis a Virgilio en la Égloga 4 Si canimus syluas, syluae sint consule dignae. [Luego se extiende en la explicación erudita de la

36. Robert Jammes, que escuchó una intervención oral de este trabajo, me procuró posteriormente, con su proverbial y admirable generosidad, la referencia de lugares paralelos gongorinos, donde el "profanar» carece de todo sentido peyorativo, a no ser que el contexto religioso así lo indique, como sucede únicamente en el último de estos tres casos: romance de 1602 «En un pastoral albergue», v. 127; romance de 1614 «Cuatro o seis desnudos hombros», v. 19; y romance de 1620 «Minguilla la siempre bella», v. 17. En particular los versos del romance de 1614 (tan cercano a las Soledades de Góngora, como señaló el propio Jammes en su edición de las mismas, 1994, pp. 51-55) ilustran sobremanera sobre un "profanar» muy próximo al utilizado en el soneto: «Este ameno sitio breve, / de cabra, apenas, montes / profanado, escaló un día / mal agradecida fe» (vv. 17-20). Agradezco muy de veras tan doctas informaciones que me han hecho y me seguirán haciendo reflexionar sobre el tema. 
dignidad y ocupación de los cónsules romanos]... Por esta misma razón se llamaron Consultos los Doctores en la Jurisprudencia, a que aludió Don Luis, llamando al Doctor Amaya prudente Cónsul ${ }^{37}$.

Añadamos que don Francisco de Amaya, catedrático de Derecho en la Universidad de Osuna, escribió en defensa de Góngora (y en respuesta al Antídoto de Jáuregui) un Antiantídoto o Apología por las «Soledades», obra hoy perdida ${ }^{38}$.

La preocupación por los realia que trasparenta el comentario de Salcedo Coronel parece ir demasiado lejos en este caso. Sobre todo porque $-\mathrm{a} \mathrm{mi}$ parecer, insisto- violenta la lectura que deriva de la lógica textual y perturba las expectativas del lector. En efecto, después de un vocativo nominal («amiga Soledad») y un verbo en imperativo («restituye») resulta muy forzado que la misma estructura en el siguiente cuarteto deba ser leía como un nominal sujeto (un "prudente cónsul») y un verbo en presente de indicativo («busca») en lugar de imperativo. Pero los críticos posteriores (salvo Molho que -como quedó dicho- parecía desconocer el comentario de Salcedo al soneto) siguieron sin discusión esa senda abierta por Salcedo e insistieron en ella, aportando incluso novedades en la misma dirección: para Orozco Díaz el «prudente cónsul» era Andrés de Almansa y Mendoza ${ }^{39}$, difusor de la Soledades en la corte y autor de unas Advertencias para la inteligencia de las mismas ${ }^{40}$; para Bataillon, el duque de Béjar ${ }^{41}$, dedicatario del poema. Aunque fue la propuesta de Salcedo Coronel a favor de Amaya la que siguió teniendo más crédito; tanto como para ser convertida por Robert Jammes en dato sobre el que asegurar la fecha del perdido Antiantídoto en el verano de $1615^{42}$.

Creo que no es preciso sentirse obligado a concretar el "cónsul» en una persona real, puesto que personificada está la Soledad con su tratamiento alegórico desde el principio del soneto; ni tampoco es necesario identificarlo con alguien que sea jurisconsulto. De hecho, la mención de Góngora nada tiene que ver con el verso de Virgilio -citado por Salcedo- referido a su protector Asinio Polión («Si canimus syluas, syluae sint consule dignae», Égl. IV, 3: en Virgilio se desea que las selvas sean dignas del cónsul Polión; en Góngora el

37. 1644, pp. 617-618.

38. De la que habla el propio Amaya en cartas a Pellicer de fechas posteriores, encontradas por L. Iglesias, 1983.

39. E. Orozco, 1973, p. 215.

40. Cf. E. Orozco, 1961 y 1969; y ahora B. López Bueno, 2012b.

41. Según hizo saber por carta a Molho y éste transmite (1978, p. 71 n. 36).

42. "Al parecer, Amaya -dice Jammes- aprovecharía el período veraniego del ańo de 1615 [fecha que proporciona el soneto "Restituye..."], cuando estaba "de impedimentos desatado", para buscar, lejos del claustro de la Universidad de Osuna, el "claustro verde" de la Naturaleza" (1994, p. 636); o "...los que, como el prudente cónsul Francisco de Amaya, se dedican a un trabajo intelectual, buscando la tranquilidad necesaria en el jardín cercado (claustro verde) de su casa de Antequera, para mejor investigar las dificultades (claustro) de las Soledades, poema de la Naturaleza (verde), lejos de las obligaciones del claustro universitario (de impedimentos desatado)" (ibid., p. 640). 
cónsul es ya digno de las selvas ${ }^{43}$ ), salvo -y es muchísimo- la música virgiliana que evoca. Góngora nos lleva una vez más a su territorio de reminiscencias cultas y latinas, en el que, de paso, ha logrado calar en la conciencia del lector las syluae virgilianas (por su remisión desde la voz selvas), con todo lo que ella implica en las Soledades.

Pero todavía los tercetos nos reservan sorpresas. Como decía al principio, en ellos reside otra novedad de la interpretación que propongo.

¡Quán dulcemente de la encina vieja tórtola viuda al mismo bosque incierto apacibles desuíos aconseja!

Endeche el siempre amado esposo muerto con voz doliente, que tan sorda oreja tiene la soledad como el desierto.

Su carácter conclusivo y epifonemático es manifiesto. Como en tantos y tantos sonetos del Siglo de Oro espańol, estos tercetos cierran a modo de epílogo. Pareja a esa característica constructiva o formal, va otra -también común en los sonetos de la época- de orden semántico, pues los tercetos interiorizan el sentido para servir de reflexión y aplicarlo a modo de moraleja (sentimental o moral).

El primer terceto nos lleva a la contemplación de un animal largamente familiarizado con la literatura occidental, la tórtola viuda y sus melancólicas quejas en el bosque (que remite de nuevo a Virgilio: «Nec gemere aëria cessabit turtur ab ulmo», Égl. I, 58). La tórtola, en su duelo, «aconseja desvíos», es decir, 'retiros' al bosque, que es «incierto» (un nuevo cultismo de acepción, del latino incertus), es decir, 'inseguro', 'lleno de incertidumbres'. Nunca podremos tener total certeza, tal como está construida la frase, de si «bosque» es complemento indirecto ('aconseja al bosque') o circunstancial ('aconseja retiros en el bosque'), pues aunque pudiera parecer más lógica esta segunda interpretación, el diálogo con la naturaleza que la tórtola establece (dentro del general animismo gongorino) no hace descartable la primera lectura, porque, al fin y al cabo, el bosque es su único interlocutor posible, y también porque esta interpretación justifica mejor el adjetivo "mismo" ('aconseja al propio bosque', 'aconseja incluso al bosque'), además de añadir -a tenor de lo que diré en seguida- una mayor coherencia en la interpretación conjunta de los tercetos.

La aparición de la tórtola implica todo un simbolismo que orienta decididamente el sentido del texto. Desde la literatura grecolatina, y continuando en las interpretaciones cristianas $^{44}$, este animal pasa por ser ejemplo extremo de castidad y fidelidad, pues tras la muerte de su compañero, se retira de los

43. El movimiento a la inversa que el suscitado por el verso de Virgilio es defendido también por Antonio Alatorre (1996), bien que siguiendo en la línea de identificar el «cónsul» con una persona real y concreta: Cincinnato en este caso, a quien deben imitar las Soledades en su sabia decisión de volver al retiro.

44. Véase el estudio y monumental repertorio de J. J. García Arranz, 2010, pp. 713-725. 
lugares habitados a gemir, siempre posando sobre árboles secos, en los yermos y en los desiertos. De ahí que sea igualmente símbolo de la existencia solitaria ${ }^{45}$.

Como anillo al dedo, pues, en el soneto que comentamos. El gemir de la tórtola es tan inútil como la queja del poeta, pues ni la una hará volver al esposo muerto, ni el otro a su Soledad-poema. Y sobre todo el parangón, por lo que atañe a la literalidad del texto, se manifiesta en que ambos se dirigen a interlocutores sordos: «...que tan sorda oreja / tiene la soledad como el desierto». Y ahí está, de nuevo, el concepto que el término soledad esconde en su disemia a lo largo de todo el soneto, porque la «soledad» del v. 14 tanto es la soledad-bosque ante la que gime la tórtola (plano real y explícito), como la Soledad-poema a la que exhorta el poeta (plano figurado e implícito). Y ambas soledades tienen la oreja tan sorda como el desierto. El soneto se cierra así de modo contundente, inequívocamente concluso. Con unos términos, además («sorda oreja», «desierto»), que están llenos de ecos bíblicos a partir de la célebre frase de Isaías "Vox clamantis in deserto», luego recogida por todos los evangelistas, como bien señaló R. Jammes ${ }^{46}$. Es, sin duda, una fórmula de enorme eficacia expresiva para sellar el soneto.

El poeta clama en el desierto: ese podría ser el lema de esta Alegoría de la primera de sus «Soledades». El poeta intenta persuadir a su poema para que regrese, para que se restituya a su ser. Es la solicitud explícita en los cuartetos. Viendo que es imposible su intento, desiste melancólica y desengañadamente. Es la conclusión en los tercetos. Pero ahora lo dice implícitamente, amparándose en la imagen gemidora y solitaria de la tórtola: 'que siempre cante endechas', 'que siempre haga duelo con sus lamentos fúnebres'..., 'que de nada sirve, porque nadie la escuchará.

Así entendidos los tercetos, se salva la poca claridad en su interpretación, que arrancaba del primer e ilustre comentarista ${ }^{47}$, y se salva también el «salto conceptual» que Carreira achacaba al soneto. Porque, en efecto, la identificación tórtola-Soledad ${ }^{48}$ produce distorsiones insalvables para su correcta comprensión,

45. Para el simbolismo de la tórtola en el soneto que comentamos es imprescindible el ensayo de G. Poggi, 2009; y para su significación en el conjunto de la poesía gongorina, resulta de obligada consulta el de N. Ly, 2011, en el que tras repasar el motivo de la tórtola en otros poetas áureos, se pone de manifiesto el peculiar, e incluso contrastivo, uso que del mismo hace Góngora.

46. 1994, p. 642. A esta información Jammes añade otras complementarias muy oportunas, como la aparición de la voz solitudo en el mismo versículo de Isaías, XL 3, o la frecuente presencia en la Vulgata del mismo término como equivalente de desierto (Ibíd.). Todo ello abunda en una identificación que está en la base del concepto gongorino de Soledad.

47. Del primer terceto dice Salcedo Coronel: «Con este ejemplo quiere significar Don Luis quán seguro es desuiarse de la facilidad humilde en asuntos grandes, como el de la Soledad»; y del segundo «Pero vanamente se fatiga en persuadir esto, lamentando con dolorosa voz su amado esposo muerto, porque la soledad tiene tan sorda oreja como el desierto: esto es, porque tan sordos son los troncos y las piedras como los hombres ignorantes y obstinados» (1644, p. 619).

48. "Góngora -dice Carreira- hace una equivalencia entre la tórtola, que emite su planto sin preocuparse de quien la escucha, y la Soledad, pájaro ladino que debe huir del poblado y cantar para quienes lo busquen a solas y en silencio» (2009, p. 525). También siguieron la misma interpretación Pérez Lasheras y Micó: «Parece clara la equivalencia que en los tercetos se establece 
incluso desde la pura literalidad del texto, ya que la coherencia poética no parece permitir ese -en efecto- salto, producto de que la Soledad pase, sin transición, de ser elemento apelado o pasivo, a convertirse en elemento activo, aunque sea por la vía de la equivalencia metafórica; y la coherencia semántica no permite -como dije al principio- que si es la Soledad, en su equivalencia o identidad con la tórtola, la que emite las quejas, sea al mismo tiempo a quien se reprocha que no las escuche (por su «sorda oreja»).

La lectura literal del soneto nos ha permitido respetar la coherencia textual (en sus implicaciones gramaticales, semánticas y poéticas) incardinando en ella -porque sólo de ella derivan- las proyecciones simbólicas. De hecho, y como queda claro desde el título del soneto, estamos ante una alegoría, y por tanto ante un doble plano permanente. La Soledad es el poema y es el lugar apartado (selva o bosque) donde habitan los desiderata de silencio, de paz y de "soledad». En esto el soneto escapa a sus propios límites para convertirse en una de las composiciones más emblemáticas de su autor.

Sabido es que la mejor poesía de Góngora es la que se deja llevar por la incitación de soledad que el poeta perfila en los famosos tercetos de $1609^{49}$; en ellos proyecta la idea de soledad como un anhelo vital y el concepto de soledad como un recurso artístico ( $(\mathrm{O}$ h Soledad, de la quietud divina / dulce prenda, aunque muda, ciudadana / del campo, y de sus ecos convecina»). La soledad, como gran determinante de su inspiración, será desde entonces una actitud interior que se refleja en un visionado natural, al quedar sentimiento y paisaje fundidos como dos caras de la misma moneda. Su concreción más genial la consigue en el poema que incluso lleva ese nombre, las Soledades. Y en ese mismo juego de espejos (poema/actitud-paisaje) se desenvuelve el soneto que analizamos.

Pues bien, tras perseguir el sentido literal y apuntar el simbólico, es preciso ahora para completar el análisis indagar sobre el alcance del soneto en su contexto más inmediato, que no es otro que un determinado momento en la trayectoria de la polémica suscitada en torno a Góngora tras la aparición de sus dos poemas mayores. Si se da por hecho que ningún texto está exento de conexiones con el entorno, y por tanto que ningún estudio responsable puede obviarlas, es evidente que un texto como el soneto que nos ocupa, inserto en la cadena de una polémica de ataques y contraataques, de réplicas y contrarréplicas, no puede ser en modo alguno explicado olvidando esa circunstancia. Porque aquí la circunstancia deja de ser accidental para convertirse en esencial en

entre la Soledad (definida en el v. 4 como un "pájaro ladino") y la tórtola (emblema de la fidelidad de la viuda): ni una ni otra se preocupan por la segura incomprensión o inutilidad de su canto, y ambas se sienten satisfechas en su condición de condenadas -diríamos- a predicar en el desierto» (1991, p. 290).

49. «¡Mal haya el que en señores idolatra...». Cf. J. M. Micó, 1990, pp. 265-276; y A. Sánchez Robayna, 1993, 83-99. 
la intención del autor; y con el conocimiento de la intención autorial -o el intento de conocerla- estamos en mejores condiciones para la comprensión de un texto.

Tenemos la suerte para nuestro soneto de la datación en 1615 por Chacón, además de la orientación precisa del título, Alegoría de la primera de sus "Soledades» ${ }^{50}$. No necesitaría más aval la fecha proporcionada por Chacón, pero queda además ratificada por otra circunstancia: el hecho de que este soneto forme parte de un conjunto de cuatro composiciones de Góngora situadas en medio de la trifulca epistolar habida entre Lope de Vega y él (o sus respectivos círculos) entre septiembre de 1615 y enero de $1616^{51}$. La sucesión de cartas y sus fechas, tal como las transmite el ms. Gor ${ }^{52}$, es la siguiente: 1/ Carta escrita a don Luis de Góngora en razón de las Soledades, 13 de septiembre de 1615; $2 /$ Respuesta de don Luis de Góngora, 30 de septiembre de 1615; 3/ Carta de don Antonio de las Infantas y Mendoza respondiendo a la que se escribió a don Luis de Góngora en razón de las Soledades, 15 de octubre de 1615; y 4/ Respuesta a las cartas de don Luis de Góngora y de don Antonio de las Infantas, 16 de enero de 1616. (La anonimia de la primera y de la última es estratagema para ocultar la voz de Lope de Vega, o de los suyos.) El soneto que nos ocupa y las otras tres composiciones están copiados entre la penúltima carta y la última. Se trata de los siguientes poemas: sonetos «Restituye a tu mudo horror divino", "Con poca luz y menos disciplina», "Pisó las calles de Madrid el fiero», y composición en dos décimas que comienza «Por la estafeta he sabido».

A esas composiciones se refiere indudablemente Lope en la carta de 16 de enero que cierra la serie, cuando, tras haber afeado a Góngora al principio de

50. El comentarista Pellicer creyó (erróneamente, aunque su lógica era buena, como luego se dirá) que el soneto contestaba a las críticas surgidas contra la Soledad segunda: «Del mismo modo se portaron sus émulos, reprehendiendo el estilo, las metáforas, las alusiones y demás tropos de que vsa con frequencia don Luis, que se desaogó de las calumnias en otro soneto, no menor y más grave. "Restituie a tu mudo horror diuino..." ". Así lo dice en su Vida de Don Luis de Góngora. Este escrito, conocido como Vida mayor, no pudo publicarse, como quiso Pellicer, en sus Lecciones solemnes, tal como allí explica en un breve preámbulo $A$ los letores $(1630$, p. 17) y sólo se publicó a principios del siglo XX, a partir del Ms. 3918 de la BNE, por R. Foulché-Delbosc (1915, pp. 578588); más tarde el mismo hispanista francés la incluyó como uno de los Apéndices de su edición Obras de Góngora (1921, III, pp. 296-308), de donde tomo la cita (p. 302).

51. Remito a mi trabajo de 2011, pp. 239-270, en el que justifico por qué esas fechas, y no las de 1613-1614, como se venían dando, para el cruce de cartas entre Lope y Góngora. Entre otras argumentaciones allí esgrimidas, una muy principal es la solvencia del que llamamos ms. Gor, uno de los seis testimonios que recogen la polémica epistolar, aunque sólo éste contiene el total de las cuatro cartas que la conforman. Para más detalles sobre el ms. en cuestión véase nota siguiente.

52. Así se conoce entre los gongoristas por haber pertenecido al aristócrata granadino duque de Gor; hoy se custodia en la Biblioteca de la Fundación Bartolomé March en Palma de Mallorca, ms. B106-V1-36. Lleva por título en el lomo Contra la pestilente poesía, pero además del Antídoto de Jáuregui, contiene los tres escritos de apoyo a Góngora escritos por Francisco Fernández de Córdoba, abad de Rute, el Examen del Antídoto, la Apología por una décima y el Parecer (por ese orden), las Advertencias de Almansa y Mendoza y finalmente, entre los ff. $161 \mathrm{r}^{\circ}$ a $197 \mathrm{v}^{\circ}$, van las cuatro cartas. Las cuatro composiciones de Góngora, copiadas entre la tercera y la última carta, ocupan los ff. 177ro-178vo. Cf. J. M. Daza, 2011, 271-287. 
la misma su costumbre de responder a las críticas con burlas («mas visto que Vm. prosigue en hazer versos con su acostumbrada graciosidad...»), le espeta irónicamente casi al final:

Entiendo bien que las décimas y sonetos, que andan por ay en raçón destas materias publicadas después de su primera respuesta de $\mathrm{Vm}$. son de otro, o por lo menos ya que no lo sean, lo parecen [...]. Ya que Vm. es colérico y amigo de gozar en verso de su ingenio, pudiera contentarse con tener buen nombre en las obras y cosas de fazecias, o pensando tratar materias graves no aver gastado tanto tiempo en lo primero ${ }^{53}$.

Se ve por tanto que Góngora acabó de completar su muy seria carta de 30 de septiembre con posteriores versos de índole satírico-burlesca: justamente los que el ms. de Gor recoge antes de la carta última de Lope. Pero, ¿qué son y qué pretenden esas composiciones? El soneto «Pisó las calles de Madrid el fiero / monóculo galán de Galatea...» es una burla contra los perrillos ladradores ("gozques») que han atacado su Polifemo, "crítica turba» a la que el cíclope, por toda explicación, responde con dos ventosidades. También está en Chacón fechado en 1615. El otro soneto y las décimas (que no están en Chacón, sin duda por las alusiones satíricas personales en ellos contenidas) son reactivos a los ataques sufridos por las Soledades (en rigor, habría que decir por la Soledad primera, la única difundida hasta ese momento). En las décimas «Por la estafeta he sabido / que me han apologizado...» Góngora reacciona contra quienes lo acusan de oscuridad, en unos dardos que van directos a Lope y desde luego a Jáuregui y a su Antídoto contra la pestilente poesía de las Soledades recién terminado ${ }^{54}$. También va contra la censura de Jáuregui, y de una manera decidida y directísima, el soneto "Con poca luz y menos disciplina, / al voto de un muy crítico y muy lego...». Todo él es un juego de equívocos por el parangón que se establece entre la procesión madrileña de penitencia de la Virgen de la Soledad el día de Viernes Santo y el camino, también de penitencia, que a la primera Soledad le está deparando un «muy crítico y muy lego», $[\ldots]$ que «duerme en español y sueña en griego» y que está «de pasión ciego", es decir, Jáuregui, según he expuesto en otro lugar ${ }^{55}$.

A la vista de estas tres invectivas satírico-burlescas, que son los dos sonetos y la composición en décimas, podemos preguntarnos qué hace a su lado el soneto «Restituye a tu mudo horror divino». La respuesta es muy fácil. El tono de amargura y melancolía, aunque también de rabia contenida, presente en este soneto, en el que su autor manifiesta el deseo (inútil ya) de 'recoger' su Soledad primera $^{56}$, presa entre tantos enemigos, contrasta desde luego con la

53. Sigo el texto ofrecido por Orozco, 1969b, pp. 316-326.

54. Un análisis de las décimas, junto con la interpretación del término «apologizar», puede verse en mi trabajo López Bueno, 2013.

55. López Bueno, 2012a. Allí expongo cómo la diana de Góngora es Jáuregui, que «sueña en griego", por haber sido el ilustrador con veinticuatro grabados de la obra del jesuita sevillano Luis del Alcázar, Vestigatio arcani sensus in Apocalypsi (Amberes, 1614), entendiendo Apocalipsis como «sueño» o «revelación» de Juan.

56. Como antes dije, Pellicer se equivocó al creer que el soneto iba dirigido a la Soledad 
actitud de poderío en el uso del sable satírico presente en los otros dos sonetos y en la composición en décimas. Pero todos ellos, forman parte de un mismo contexto: el de la defensa y/o el ataque en un momento, el del otońo de 1615, de especial dificultad para Góngora.

Con la difusión en Madrid del Polifemo y la Soledad primera a partir de mayo de 1613 se abre un período de incertidumbres cronológicas sobre su recepción del que realmente tenemos muchas lagunas. Sabemos que Góngora, consciente de la novedad y de la ruptura que suponían sus Soledades, quiso pertrecharse de opiniones muy doctas al respecto, y para ello solicitó pareceres a humanistas de pro, como Pedro de Valencia, Francisco Fernández de Córdoba (abad de Rute) o Tamayo de Vargas. Las fechas de sus respuestas nos sitúan en un arco temporal que va de junio de 1613 (la de Valencia), pasando por enero de 1614 (la del Abad) a junio de 1614 (la de Tamayo) ${ }^{57}$. Pero tan autorizadas opiniones de apoyo (ni siquiera el extenso comentario de Manuel Ponce Sylva a las Soledades ${ }^{5}$ ) pudieron contrarrestar la avalancha en contra, si hemos de hacer caso al publicista Andrés de Almansa y Mendoza, que dice escribir sus Advertencias para la inteligencia de las Soledades para salir al paso "de un torvellino de pareceres y objetos (si se les puede dar este nombre) que la ventolera de algunos con título de doctos, curiosos y valientes ingenios an levantado contra las Soledades ${ }^{59}$. Aunque la fecha de estas Advertencias resulta ser una de las grandes cuestiones debatidas de la primera fase de la polémica gongorina, lo más probable es que fueran de 1614, y, en cualquier caso, son el detonante -y a eso es a lo que vamos- de la pelotera epistolar habida entre Lope y Góngora. Es cierto que hay mucho de excusa fingida por parte de Lope para cargar sobre las espaldas de Almansa la causa de la carta del supuesto «amigo» (es decir, él mismo) de 13 de septiembre de 1615, pero lo indudable es que le sirvió en bandeja la ocasión que él llevaría esperando mucho tiempo. De todo ello he tratado en un trabajo reciente ${ }^{60}$.

El «amigo» muestra en la carta su extrańeza por el encargo de difusión y comentario de las Soledades a alguien como Mendoza, teniendo Góngora-dice en clave irónica- tan doctos amigos, y le recomienda que retire su poema. En la Respuesta de 30 de septiembre Góngora, que se muestra muy enojado por el

segunda (Vida mayor de Góngora), lo que no es posible porque en 1615 la Soledad segunda (o mejor, lo que llevara escrito de ella) permanecía aún en el ámbito de la privacidad. La lógica de Pellicer sin embargo era buena al considerar globalmente la petición de 'retirada' del poema que allí hace Góngora. Según su interpretación el soneto «Pisó las calles...» iba referido a la recepción del Polifemo, "Con poca luz...» a la Soledad primera, y «Restituye...» a la Soledad segunda.

57. Para más precisiones sobre estos pareceres y sus fechas, en el confuso contexto cronológico de recepción de la Soledad primera, cf. López Bueno 2011.

58. Cf. Dámaso Alonso, 1978 y 1982, pp. 501-524. Hay que saludar con verdadero alborozo la reciente reaparición de este comentario de Ponce, que se creía perdido y del que actualmente Antonio Azaustre prepara una edición dentro del proyecto «Pour une édition digital de la querelle de Góngora», dirigido por Mercedes Blanco (Universidad de Paris IV-Sorbonne).

59. Cf. E. Orozco, 1961 y 1969, p. 198. Sobre este texto preparo actualmente una edición dentro del proyecto mencionado en la nota anterior.

60. López Bueno, 2012b. 
anonimato de su interlocutor, hace una defensa rotunda de la oscuridad poética como credo estético y responde por Mendoza ante los ataques. Luego vendrá, en la tercera misiva, un refuerzo a la carta de Góngora por parte de un amigo, ahora verdadero, Antonio de las Infantas. Y finalmente, como queda dicho, cierra la serie otra carta de Lope, en este caso una carta larga y en cierta forma demoledora. Posiblemente las circunstancias inmediatas, con el giro que está dando la polémica por la aparición del Antídoto de Jáuregui, han hecho crecerse a Lope frente a su rival.

Si las cosas estaban mal en septiembre de 1615 cuando Góngora hace la Respuesta (con el «torbellino de pareceres» en contra, rematado por la carta de Lope de 13 de septiembre), todo ello se convierte en tortas y pan pintado al aparecer un furibundo ataque titulado con rechifla Antídoto contra la pestilente poesía de las "Soledades», aplicado a su autor para defenderle de sí mismo, escrito por el poeta sevillano Juan de Jáuregui. Ahora ya no eran papeles volanderos, ni cartas anónimas, sino una censura en toda regla, que se muestra constantemente en contacto con el texto que comenta, censura adobada, por ańadidura con gran sentido del humor, escarnios incluidos.

Góngora acusa el golpe. Y lo devuelve en forma de versos. ¿Dónde?: en las cuatro composiciones que el colector del ms. de Gor recoge entre la tercera y la cuarta carta del rifirrafe epistolar con Lope, es decir, en composiciones escritas en otońo de 1615, cuando Góngora conoce que ha sido «apologizado». Se revuelve, al tiempo dolorido y enojado, contra sus críticos, y muy en especial contra Jáuregui, en quien está pensando concretamente al escribir los sonetos "Restituye a tu mudo horror divino» $\mathrm{y}$ "Con poca luz y menos disciplina ${ }^{61}$. El enojo y la rabia hacen su curso, a la ofensiva, en los tres ataques a lo burlesco. El sentimiento dolorido se explaya, a la defensiva, en el soneto "Restituye a tu mudo horror divino». Un halo de melancolía envuelve sus catorce versos para venir a decir: 'no mereció la pena'; 'difundir mi poema fue como «dar piedras preciosas a los animales de cerda»'. Por eso el soneto no tiene el afán combativo de otras piezas polemistas. Cierto que es reactivo a la polémica, pero sin el tono efímero propio de ella. Porque ahora es una reacción reflexiva y distante; secundaria, tras haberse interiorizado el disgusto y producir una respuesta desengañada. Cuestión imposible será saber si ese desengaño del poeta orienta los reproches implícitos a sí mismo, por haber traicionado el espíritu del poema enviándolo a la corte en busca de notoriedad y medro ${ }^{62}$,

61. La transmisión conjunta y sola de ambos sonetos en el ms. BNE 3965, Góngora, Soledades (que contiene el Antídoto y las notas de Francisco de Amaya para el Antíantidoto, además de estos dos sonetos) habla por sí misma para esta identificación. El mismo contenido se encuentra en el ms. 1685 de la Biblioteca Central de Barcelona, posiblemente copia del anterior (cf. B. Ciplijauskaité, 1981, pp. 44-45).

62. Como quería E. Orozco (1963, 1969, pp. 21-49). Sobre este asunto, íntimamente relacionado con el inacabamiento de las Soledades es ahora imprescindible el finísimo trabajo de A. Sánchez Robayna, 2011, pp. 289-312. 
como quería Orozco $^{63}$ (1963), o, más verosímilmente, los orienta hacia los demás, incapaces de percibir «lo misterioso que encierra». En cualquier caso, el grito sincero de Soledad que el poema contenía (como cenital recreación de la búsqueda de la propia soledad espiritual) no debió salir de sí mismo, porque ni fue entendido ni valorado como merecía. Es, justamente, lo que dice el soneto comentado. De manera explícita, e inmediata, en los cuartetos, exhortando a la Soledad a la debida "restitución»; de manera implícita, y mediata, en los tercetos, mostrando el desengaño de quien, como la tórtola, se queja en vano.

\section{Bibliografía citada}

Alatorre Antonio, «Notas sobre las Soledades (a propósito de la edición de Robert Jammes)», Nueva Revista de Filología Hispánica, XLIV, 1996, pp. 57-97.

Alonso Dámaso, «Manuel Ponce, primer comentarista de Góngora» (1978), en Obras completas VI, Madrid, Gredos, 1982, pp. 501-524.

Carvallo Luis Alfonso de, Cisne de Apolo. De las excelencias y dignidad y todo lo que al arte poética y versificatoria pertenece, Medina del Campo, por Ian Godínez de Milis, 1602; ed. de Alberto Porqueras Mayo, Madrid, CSIC, Biblioteca de Antiguos Libros Hispánicos, 1958.

Carreira Antonio, ed., Luis de Góngora, Antología poética, Madrid, Castalia, 1986; $2^{\text {a }}$ ed. rev. y aum., Barcelona, Crítica, 2009.

Carreira Antonio, «El Manuscrito Chacón: A tal señor, tal honor», en Obras de D. Luis de Góngora, reconocidas y comunicadas con él, por D. Antonio Chacón ..., 1991, vol. III, pp. VII-XXI; reimpr. en Gongoremas, Barcelona, Ediciones Península, 1998, 75-94.

Ciplijauskaité Biruté, ed., Luis de Góngora, Sonetos, Madison, Hispanic Seminary of Medieval Studies, 1981. Ed. facsímil: Málaga, Consejería de Cultura de la Junta de Andalucía, 2007.

Covarrubias Sebastián de, Tesoro de la lengua castellana o española (1611). Ed. facsímil: Madrid, Turner, 1979.

Daza Juan Manuel, «Alcance doctrinal de las polémicas gongorinas», en B. López Bueno, dir., El canon poético en el siglo XVII, Sevilla, Publicaciones de la Universidad/ Grupo PASO, 2010, pp. 125-149.

— «Los testimonios de la polémica epistolar Lope-Góngora (1615-1616), con edición de la Respuesta de Góngora», en B. López Bueno, ed., El poeta-Soledad. Góngora 1609-1615, Zaragoza, Prensas Universitarias de Zaragoza, 2011, pp. 271-287.

Foulché-Delbosc Raymond, «Vida de Don Luis de Góngora (Vida mayor) por Don Joseph Pellicer de Salas y Tovar», Revue Hispanique, XXXIV, 1915, pp. 578-588.

63. Cf. Emilio Orozco, 1963, 1969, pp. 21-49. Sobre este asunto es imprescindible ahora el finísimo trabajo de A. Sánchez Robayna, 2011. 
Foulché-Delbosc Raymond, ed., Obras poéticas de D. Luis de Góngora, New York, The Hispanic Society of America, 1921, 3 vols.

García Arranz, José Julio, "Symbola et emblemata avium». Las aves en los libros de emblemas y empresas de los siglos XVI y XVII, A Coruña, SIELAE (Seminario Interdisciplinar para el Estudio de la Literatura Áurea Española) y Sociedad de Cultura Valle Inclán, 2010.

Góngora Luis de, Obras de D. ..., reconocidas y comunicadas con él, por D. Antonio Chacón Ponce de León, Señor de Polvoranca. Al Excmo. Sr. D. Gaspar de Guzmán, Conde Olivares, Duque de Sanlúcar la Maior... Divididas en tres tomos. Ed. facsímil: Málaga, Real Academia Española/Caja de Ahorros de Ronda, 1991.

Iglesias Feijoo Luis, "Una carta inédita de Quevedo, y algunas noticias sobre los comentaristas de Góngora, con Pellicer al fondo", Boletín de la Biblioteca Menéndez Pelayo, LIX, 1983, pp. 141-203.

Jammes Robert, ed., Luis de Góngora, Soledades, Madrid, Castalia, 1994.

Lopez Bueno Begońa, «La enseñanza de la literatura: reflexiones sobre un quehacer cotidiano", Glosa, 2, 1991, pp. 159-173.

— «El enigmático soneto de Góngora Restituye a tu mudo horror divino», Filología, XLI, 2009, Universidad de Buenos Aires/Instituto de Filología "Amado Alonso», pp. 99-127.

López Bueno Begońa, dir., El canon poético en el siglo XVII, Sevilla, Publicaciones de la Universidad/Grupo PASO, 2010.

López Bueno Begoña, «El cruce epistolar entre Lope y Góngora de 1615-1616. Revisión de fechas», en Begońa López Bueno, ed., El Poeta-Soledad: Góngora 16091615, Zaragoza, Prensas Universitarias de Zaragoza, 2011, pp. 239-270.

— " "Con poca luz y menos disciplina": Góngora contra Jáuregui en 1615 o los antídotos al Antídoto», en Antonio Gargano, dir., "Difícil cosa no escribir sátiras». La sátira en verso en la España de los Siglo de Oro, Vigo, Academia Editorial del Hispanismo, 2012a, pp. 205-226.

López Bueno Begoña, «Las Advertencias de Almansa y Mendoza, el "apócrifo correspondiente" de Góngora», Criticón, 116, 2012b, pp. 5-27.

López Bueno Begoña, "Góngora apologizado. A propósito de las décimas "Por la estafeta he sabido" ", en Juan Matas, José María Micó y Jesús Ponce, eds., Góngora y el epigrama. Estudios sobre las décimas, Madrid/Frankfurt am Main, Universidad de Navarra/Iberoamericana/Vervuert, 2013, pp. 123-142.

Ly Nadine, «La dicción de la naturaleza en la poesía áurea: la tórtola de San Juan de la Cruz a Góngora», en Dolores Thion Soriano-Mollá, ed., La naturaleza en la poesía española, Vigo, Editorial Academia del Hispanismo, 2011, pp. 15-44.

Micó José María, ed., Luis de Góngora, Canciones y otros poemas de arte mayor, Madrid, Espasa Calpe, 1990.

— «El libro de Góngora», Caliope. Journal of the Society for Renaissance and Baroque Hispanic Poetry, 13 (Del verso al libro, número monográfico coordinado por Santiago Fernández Mosquera), 2007, pp. 79-91.

Millé y Giménez Juan e Isabel, eds., Luis de Góngora y Argote, Obras completas, Madrid, Aguilar, 1951. 
Molho Mauricio, «Soledades», Bulletin Hispanique, LXII, 1960; reimpr. en M. Molho, Semántica y Poética (Góngora, Quevedo), Barcelona, Crítica, 1978, pp. 39-81 (se cita por esta edición).

Orozco Díaz Emilio, "La polémica de las Soledades a la luz de nuevos textos. Las Advertencias de Almansa y Mendoza», Revista de Filología Española, XLIV, 1961, pp. 29-62; reimpr. en En torno a las «Soledades»..., 1969, pp. 148-204 (se cita por esta edición).

Orozco Díaz Emilio, «Espíritu y vida en la creación de las Soledades gongorinas (Por qué se escribieron y por qué no se terminaron)", Papeles de Son Armadans, LXXXVII, 1963; reimpr. en En torno a las «Soledades»..., 1969, pp. 21-49.

— «El Parecer del Abad de Rute sobre las Soledades (Edición y comentario de un texto inédito)», en En torno a las «Soledades»..., 1969a, 95-146.

- En torno a las «Soledades» de Góngora. Ensayos, estudios y edición de textos críticos de la época referentes al poema, Granada, Publicaciones de la Universidad, $1969 \mathrm{~b}$.

- Lope y Góngora frente a frente, Madrid, Gredos, 1973.

Pellicer de Salas y Tovar Joseph, Lecciones solemnes a las Obras de Don Luis de Góngora, Pindaro andaluz, Principe de los poetas líricos de España, Madrid, Imprenta del Reino, a costa de Pedro Coello, 1630 (BNE R-25619).

- Vida mayor de Góngora, vid. Foulché-Delbosc, "Vida de Don Luis de Góngora...», pp. 578-588; y en Obras poéticas de D. Luis de Góngora, III, pp. 296-308.

Pérez Lasheras Antonio, y Micó José María, eds., Luis de Góngora, Poesía selecta, Madrid, Taurus, 1991.

Platón, Ión o sobre la Ilíada, en Obras Completas, Madrid, Aguilar, 1993.

Poggi Giulia, «Il canto della tortora (Restituye a tu mudo horror divino)», en Gli occhi del pavone. Quindici studi su Góngora, Firenze, Alinea Editrice, 2009, pp. 73-89.

Rico García José Manuel, ed., Antídoto contra la pestilente poesía de las Soledades por Juan de Jáuregui, Sevilla, Publicaciones de la Universidad, 2002.

Roses Joaquín, Góngora: Soledades habitadas, Málaga, Publicaciones de la Universidad, 2007.

Ruiz Pérez Pedro, "Género y autores: el giro de la cuestión de la poesía», en B. López Bueno, dir., El canon poético en el siglo XVII, Sevilla, Publicaciones de la Universidad/ Grupo PASO, 2010, pp. 269-303.

Rute Abad de (Francisco Fernández de Córdoba), «Apología por una décima del autor de las Soledades», en Eunice J. Gates, Documentos gongorinos. Los «Discursos apologéticos» de Pedro Díaz de Rivas. El «Antídoto» de Juan de Jáuregui, México, El Colegio de México, 1960, pp. 144-151.

Salcedo Coronel, García de, Soledades de Don Luis de Góngora comentadas por... Dedicadas al Ilmo. y Nobilísimo Sr. Don Juan de Chaves y Mendoza..., Madrid, Imprenta Real, 1636 (BNE R-15561).

Salcedo Coronel, García de, Obras de Don Luis de Góngora comentadas. Dedicalas al Excelentíssimo Señor Don Luis Méndez de Haro... Tomo Segundo, Primera Parte [Sonetos], Madrid, Pedro Laso, 1644 (BNE R-15562).

Sánchez Mariana Manuel, «Las Obras de Don Luis de Góngora ... por Don Antonio Chacón: Historia y descripción de los manuscritos», en Obras de D. Luis de Góngora, reconocidas y comunicadas con él, por D. Antonio Chacón ..., 1991, vol. II, pp. VII-XXXV. 
Sánchez Robayna Andrés, "Los tercetos gongorinos de 1609 como epístola moral», en Silva gongorina, Madrid, Cátedra, 1993, 83-99.

— «Sobre el inacabamiento de las Soledades», en B. López Bueno, ed., El PoetaSoledad: Góngora 1609-1615, Zaragoza, Prensas Universitarias de Zaragoza, 2011, pp. 289-312.

Vilanova Antonio, "Preceptistas españoles de los siglos XVI y XVII", en Guillermo Díaz-Plaja, dir., Historia General de las Literaturas Hispánicas, Barcelona, Barna, 1953, 567-692.

- "Góngora y su defensa de la oscuridad como factor estético", en Homenaje a José Manuel Blecua, Madrid, Gredos, 1983, 657-673. 